\title{
Wavelength-Tunable Ultraviolet \\ Photodissociation (UVPD) of Heparin-Derived Disaccharides in a Linear Ion Trap
}

\author{
Amandine Racaud, ${ }^{\mathrm{a}, \mathrm{c}}$ Rodolphe Antoine, ${ }^{\mathrm{a}}$ Laure Joly, ${ }^{\mathrm{a}}$ Nathalie Mesplet, ${ }^{\mathrm{b}}$ \\ Philippe Dugourd, ${ }^{a}$ and Jérôme Lemoine ${ }^{c}$ \\ ${ }^{a}$ Université de Lyon, F-69622, LASIM, Lyon, France \\ b Sanofi-Chimie, F-04200, Sisteron \\ c Sciences Analytiques, Université de Lyon, F-69622, Lyon, France
}

A set of three heparin-derived disaccharide deprotonated ions was isolated in a linear ion trap and subjected to UV laser irradiation in the $220-290 \mathrm{~nm}$ wavelength range. The dissociation yields of the deprotonated molecular ions were recorded as a function of laser wavelength. They revealed maximum absorption at $220 \mathrm{~nm}$ for the nonsulfated disaccharide, but centered at $240 \mathrm{~nm}$ for the sulfated species. The comparison of the fragmentation patterns between ultraviolet photodissociation (UVPD) at $240 \mathrm{~nm}$ and CID modes showed roughly the same distribution of fragment ions resulting from glycosidic bond cleavages. Interestingly, UVPD favored additional cross ring cleavages of $\mathrm{A}$ and $\mathrm{X}$ type ion series enabling easier sulfate group location. It also reduced small neutral losses $\left(\mathrm{H}_{2} \mathrm{O}\right)$. (J Am Soc Mass Spectrom 2009, 20, 1645-1651) (C) 2009 Published by Elsevier Inc. on behalf of American Society for Mass Spectrometry

$\mathrm{T}$ The major advances achieved in mass spectrometry have revolutionized the structural analysis of proteins and led to the emergence of proteomic strategies. Although software-assisted de novo sequencing of peptides resulting from unknown proteins has become a routine task, the structural assignment of complex N- and O-glycans is much less trivial. Unlike proteins accurately translated from a unique template that follows a universal code, a similar set of glycosyl transferases may, across different species, build oligosaccharides of different structure according to an a priori unpredictable chronological catalysis activity.

Compared with $\mathrm{N}$ - and O-linked glycans, the issue of structural complexity is continuing to increase in the world of glycosaminoglycans. Glycosaminoglycans are linear polymerized disaccharidic repeating units containing hexuronic acids and hexosamines. Their essential roles in governing numerous biologic functions [1] have led many groups to focus their efforts on defining generic strategies based on mass spectrometry, to obtain the structural definition of these acidic oligosaccharides. In the case of oligosaccharides derived from heparin or heparane sulfate, both glucuronic and iduronic acids and glucosamine may be sulfated at their $\mathrm{OH}$ and $\mathrm{NH}_{2}$ groups. The fragmentation behavior of heparin-derived oligosaccharides has proven to be difficult to predict. Sulfate groups often impede access to

Address reprint requests to Dr. P. Dugourd, and Dr. J. Lemoine, Department of Analytical Sciences, Universite de Lyon, University Lyon 1 CNRS, UMR 5180, F-69622 Villeurbanne Cedex, France. E-mail: dugourd@lasim. univ-lyon1.fr and E-mail: jerome.lemoine@univ-lyon1.fr exhaustive structural information by collision induced dissociation (CID)-MS/MS. Indeed, when the charge state of the selected molecular ion is low, neutral $\mathrm{SO}_{3}$ losses most often predominate in comparison with glycosidic backbone cleavages [2]. This situation can be improved by combining MS/MS data resulting from different charge states.

Very recently, Amster and coworkers published outstanding results showing how promising the electron detachment dissociation (EDD) of deprotonated sulfated oligosaccharides can be in providing informative fragment ions [3]. In particular, they documented the discrimination between the $\mathrm{C} 5$ epimeric glucuronic and iduronic acids based on specific fragment ions [4]. As in CID mode, they also observed that $\mathrm{SO}_{3}$ loss can be dramatically reduced when EDD is performed on the charge states where the carboxylate group is deprotonated and subsequently subjected to electron removal [5]. A similar feature is obtained by replacing protons with sodium cations. UV and IR gas-phase photodissociation (i.e., ultraviolet photodissociation (UVPD) and infrared multiphoton dissociation (IRMPD) of positive and negative precursor ions also appears to be a very promising activation method for providing new or complementary structural information in CID. These techniques have been used for the analysis of biomolecules, such as proteins [6-11], peptides [12-16], and nucleic acids [17-19]. In the case of permethylated and fixed-charge derivatized oligosaccharides, the $157 \mathrm{~nm}$ UVPD spectra yield intense cross ring fragment ions corresponding to a high-energy dissociation pathway, 
Table 1. Name, abbreviation and structure of each heparin-derived disaccharide studied in this work

\begin{tabular}{cccc}
\hline Name & Abbrev. & Structure \\
\hline \hline Disaccharide II-H & $\Delta \mathrm{UA}-\mathrm{GlcN6S}$ & \\
Disaccharide III-H & $\Delta \mathrm{UA2S}-\mathrm{GlcN}$
\end{tabular}

useful in the assignment of branching and glycosidic linkages [20]. An alternative to UVPD is the reductive amination of oligosaccharides with a fluorophore. Hence, Wilson and Brodbelt noticed that in contrast to CID, the $355 \mathrm{~nm}$ photodissociation of fluorophorelabeled glycans produced additional nonreducing end fragment ions for improved comprehensive structural assignment [21].

With the perspective of access to new fragmentation pathways, the present work explores for the first time the merits of near UV photodissociation of polyanionic precursor ions of acidic disaccharide models in a linear quadrupole ion trap.

\section{Materials and Methods}

\section{Materials}

Disaccharides (Table 1) were obtained from Dextra Laboratories and dissolved at a concentration of $100 \mu \mathrm{M}$

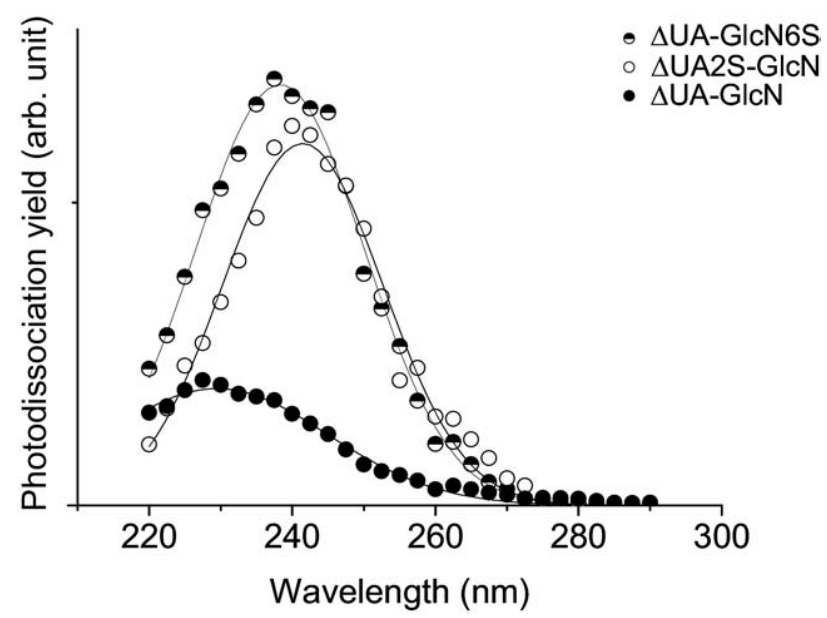

Figure 2. Photofragmentation yields measured as a function of the laser wavelength for deprotonated $\Delta \mathrm{UA}-\mathrm{GlcN} 6 \mathrm{~S}, \Delta \mathrm{UA2S}-$ GlcN, and $\Delta \mathrm{UA}-\mathrm{GlcN}$.

in $\mathrm{H}_{2} \mathrm{O} / \mathrm{MeOH}$ (50:50, vol/vol). Additional experiments were also performed on saccharose. Saccharose was dissolved at a concentration of $150 \mu \mathrm{M}$ in $\mathrm{H}_{2} \mathrm{O}$ / $\mathrm{MeOH}$ (50:50, vol/vol). Samples were introduced by electrospray ionization in negative mode. They were infused at a flow rate of $5 \mu \mathrm{L} / \mathrm{min}$ using a syringe pump.

\section{Mass Spectrometry and UV Photodissociation}

The experimental setup (Fig. 1) consists of a mass spectrometer coupled to a visible/UV tunable OPO laser. The mass spectrometer is a quadrupole linear ion trap (LTQ; Thermo Fisher Scientific, San Jose, CA, USA). A quartz window was fitted on the rear of the LTQ chamber to allow the introduction of the laser beam. The OPO laser (Panther OPO laser pumped by a 355-nm Nd:YAG Surelite; Continuum, Santa Clara, CA, USA) can be scanned from $215 \mathrm{~nm}$ up to $2 \mu \mathrm{m}$. Its main

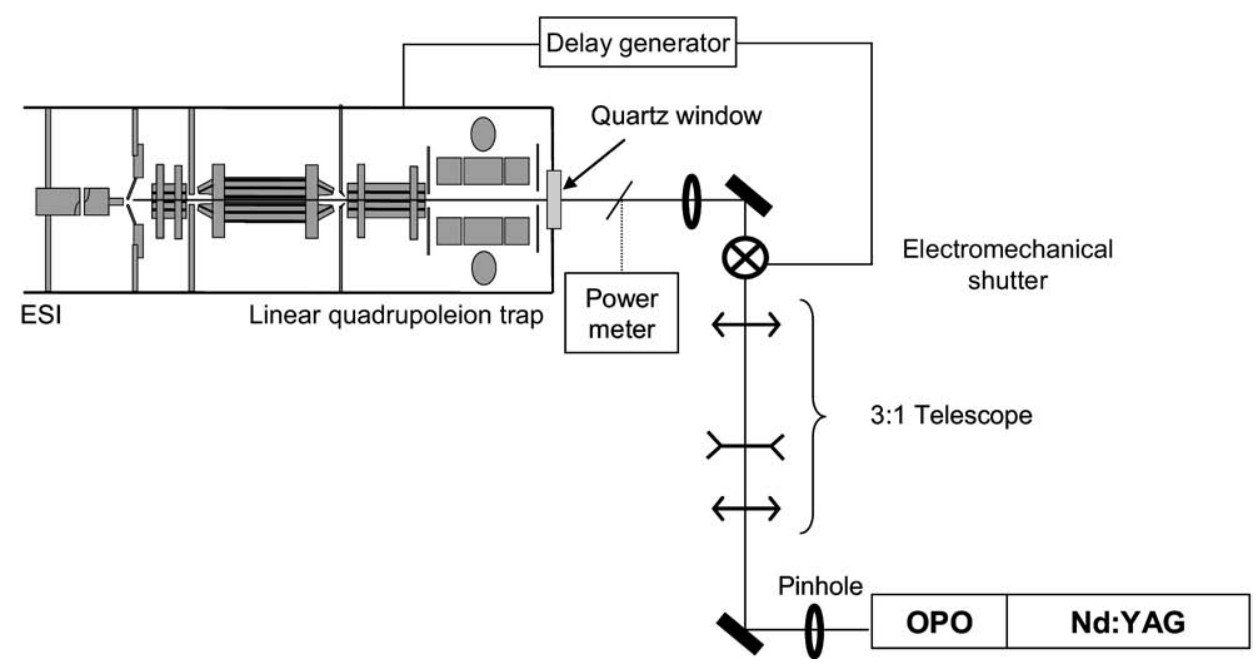

Figure 1. Schematic of the experimental set up used for UVPD in a linear quadrupole ion trap. 
characteristics are a repetition rate of $10 \mathrm{~Hz}$ and a pulse width of $7 \mathrm{~ns}$. The laser beam passes through two diaphragms, lenses (3:1 telescope), and a mechanical shutter electronically synchronized with the mass spectrometer, after which it is injected into the axis of the linear trap through a $1 \mathrm{~mm}$-diameter pinhole. The laser energy after the pinhole is between 0.1 and $1 \mathrm{~mJ} /$ pulse. The mechanical shutter is used to synchronize laser irradiation with ion trapping. To perform laser irradiation for a given number of laser pulses, we add an $\mathrm{MS}^{n}$ step with activation amplitude of $0 \%$ in the ion trap RF sequence, during which the shutter located on the laser beam is opened. The laser power is monitored in front of the mass spectrometer by a power meter (Ophir, Logan, UT, USA).

In the UVPD experiments, precursor ions were first isolated in the trap. After isolation, they were irradiated for $n$ laser shots, and the resulting mass spectrum was recorded. Optical spectra (action spectra) were obtained by systematically recording UVPD spectra as a function of the laser wavelength. The photodissociation yield is given by $\ln ($ (precursor + fragments $) /$ precursor $) /(\lambda \times$
$\mathrm{P}_{\lambda}$ ), where $\lambda$ is the laser wavelength, precursor the intensity of the precursor ion, fragments the sum intensity of the identified fragment ions and $P_{\lambda}$ the laser power measured at the entrance of the mass spectrometer. CID experiments were performed with the same apparatus. This was accomplished using helium gas at a normalized collision energy of $13 \%$ to $15 \%$ for $30 \mathrm{~ms}$. The activation $q$ value was set to 0.200 for CID and for UVPD. The isolation width for selecting the ion precursors (both for UVPD and CID) was 3 Da. A total of 50 microscans were averaged to produce a spectrum.

\section{Results and Discussion}

Whereas high photon energy $[20,22]$ enables the photofragmentation of native oligosaccharides, derivatization with a fluorophore is used for visible and near UV photofragmentation of oligosaccharides [21, 23]. To delineate the wavelength ranges that could be used in the near UV range to fragment acidic oligosaccharides, we recorded the first gas-phase optical spectra as a

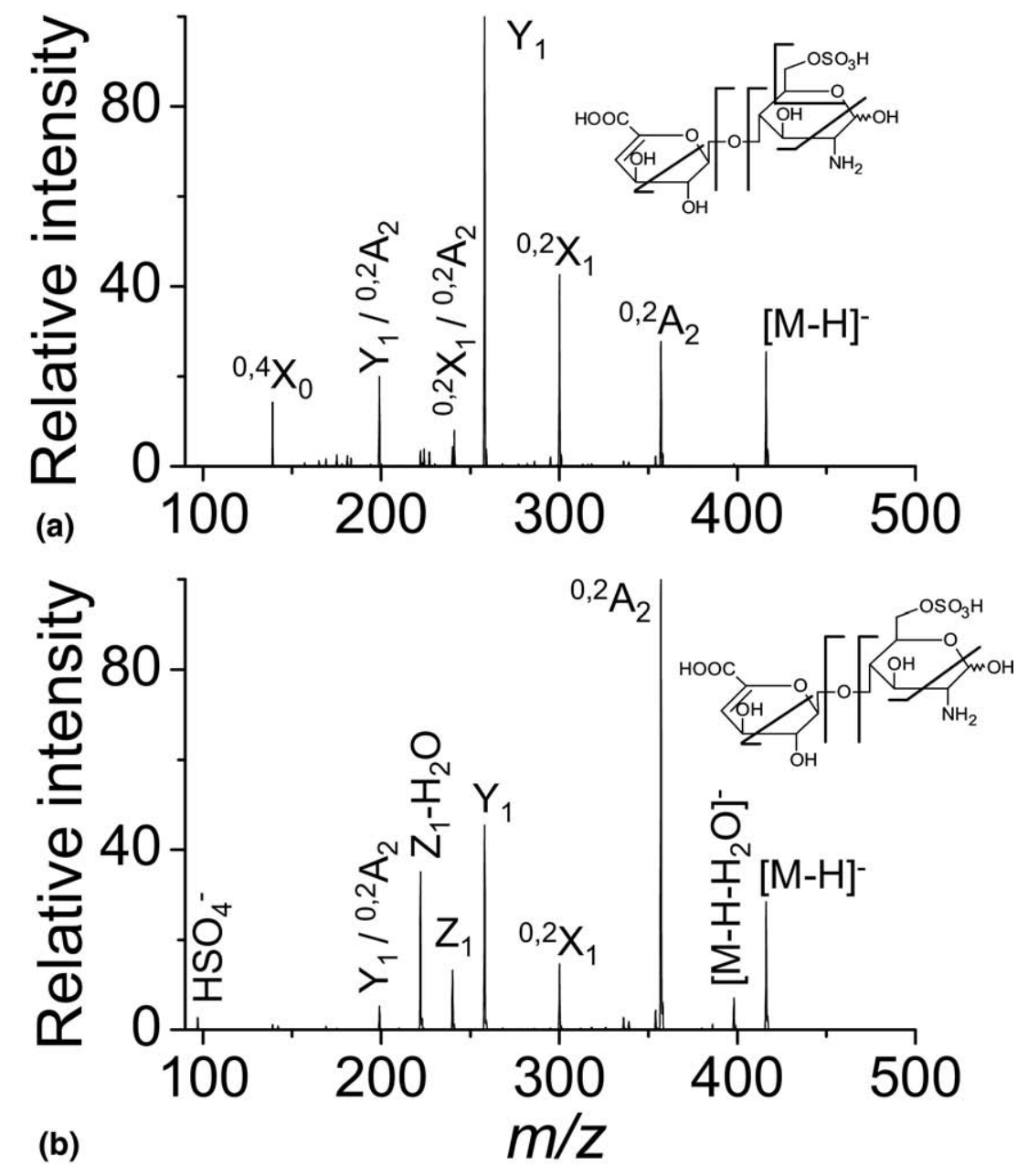

Figure 3. (a) UVPD $(\lambda=240 \mathrm{~nm})$ product ion mass spectrum of $\Delta \mathrm{UA}-\mathrm{GlcN6S}[\mathrm{M}-\mathrm{H}]^{-}$. Insert, $\Delta$ UA-GlcN6S structure with major cleavages indicated. (b) CID product ion mass spectrum of $\Delta \mathrm{UA}-\mathrm{GlcN} 6 \mathrm{~S}[\mathrm{M}-\mathrm{H}]^{-}$. Insert, $\Delta \mathrm{UA}-\mathrm{GlcN} 6 \mathrm{~S}$ structure with major cleavages indicated. 
function of laser wavelength for three heparin-derived disaccharides.

Heparins are acidic molecules that readily form negative ions. In the full MS spectrum of $\Delta \mathrm{UA}-\mathrm{GlcN} 6 \mathrm{~S}$ and $\Delta \mathrm{UA} 2 \mathrm{~S}-\mathrm{GlcN}$ molecules, the most abundant molecular ions correspond to the deprotonated species [M $\mathrm{H}]^{-}$. Less intense $[\mathrm{M}-2 \mathrm{H}]^{2-}$ ions as well as sodium adduct ions $[\mathrm{M}-2 \mathrm{H}+\mathrm{Na}]^{-}$were also observed. In the case of mono acidic $\Delta \mathrm{UA}-\mathrm{GlcN}$ heparin-derived disaccharide, only the singly charged $[\mathrm{M}-\mathrm{H}]^{-}$ion was observed. Hence, all the subsequent experiments for studying optical properties and for comparing the respective UVPD and CID dissociation pathways were performed on the singly $[\mathrm{M}-\mathrm{H}]^{-}$deprotonated species.

The measurement of the fragmentation yield for the nonsulfated uronic acid containing $\Delta \mathrm{UA}-\mathrm{GlcN}$ disaccharide, which reflects the action spectrum, displays a broad band with a maximum at $\lambda \sim 228 \mathrm{~nm}$ (Fig. 2). For the two sulfated $\Delta$ UA-GlcN6S, $\Delta$ UA2S-GlcN isomeric disaccharides, the overall dissociation yield was higher and the band was centered at $\lambda=240 \mathrm{~nm}$.

To our knowledge, these are the first gas-phase UV-optical spectra reported for oligosaccharides, whereas Polfer et al. [24] have published the possible differentiation of isomeric glucose-containing disaccharide by wavelength-tunable infrared multiple photon dissociation. More generally, these UV-optical spectra can be used as a reference for the optical absorption of carboxylate and sulfate groups in the gas phase. By contrast, the three solution spectra display an onset of absorption at $\lambda \sim 260 \mathrm{~nm}$ after which the absorption increases regularly as the photon energy increases, with no identified band above $230 \mathrm{~nm}$ (aqueous solution, 100 $\mu \mathrm{M}$ at $\mathrm{pH}=5$, spectra not shown). According to time-dependant density functional theory (TDDFT) calculations performed for small molecular mimics with sulfate and carboxylate groups (results to be published), the absorption in this region is mainly due to the

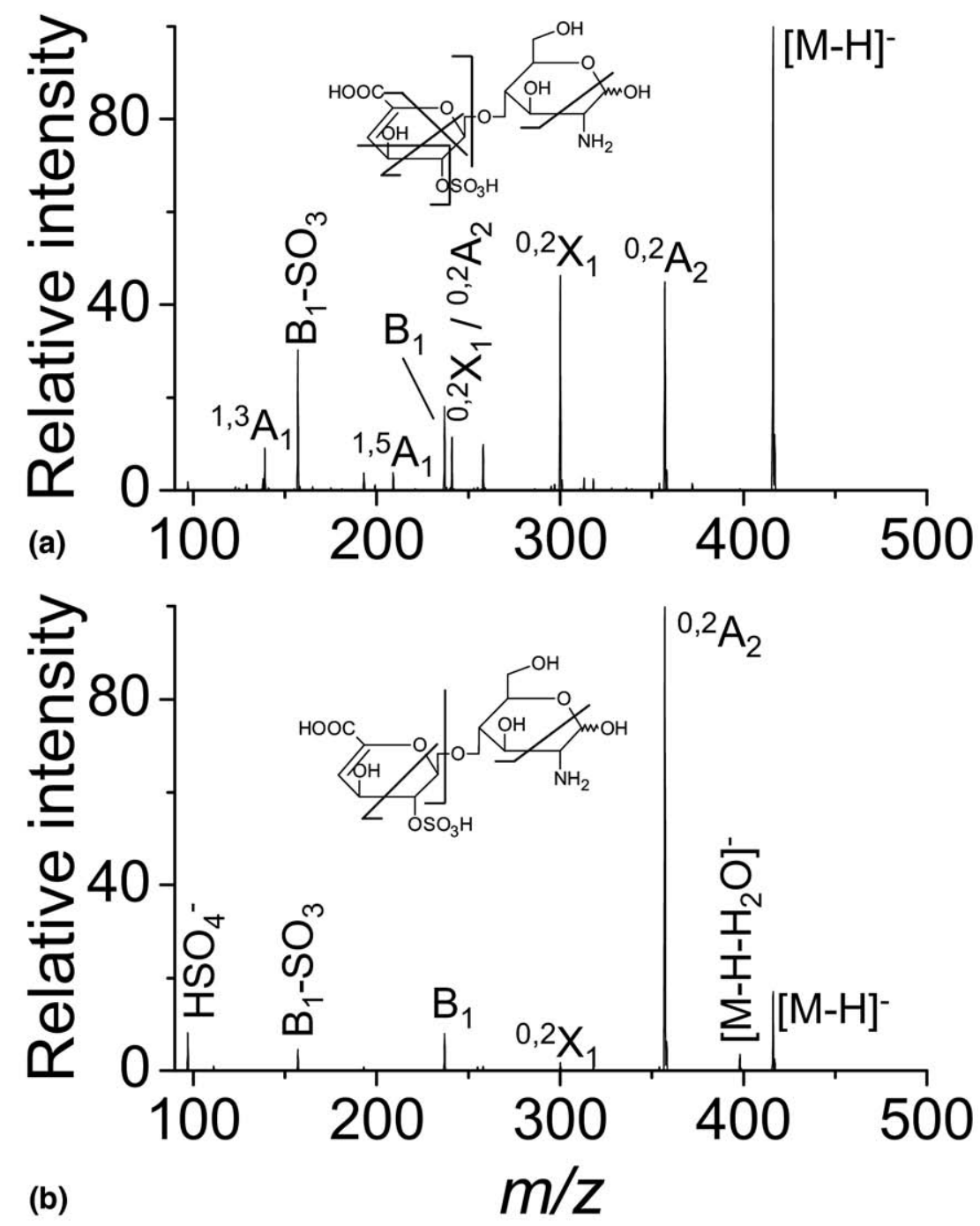

Figure 4. (a) UVPD $(\lambda=240 \mathrm{~nm})$ product ion mass spectrum of $\Delta \mathrm{UA2S}-\mathrm{GlcN}[\mathrm{M}-\mathrm{H}]^{-}$. Insert, $\triangle \mathrm{UA2S}-\mathrm{GlcN}$ structure with major cleavages indicated. (b) CID product ion mass spectrum of $\Delta \mathrm{UA2S}-\mathrm{GlcN}\left[\mathrm{M}-\mathrm{H}^{-}\right]^{-}$. Insert, $\Delta \mathrm{UA} 2 \mathrm{~S}-\mathrm{GlcN}$ structure with major cleavages indicated. 


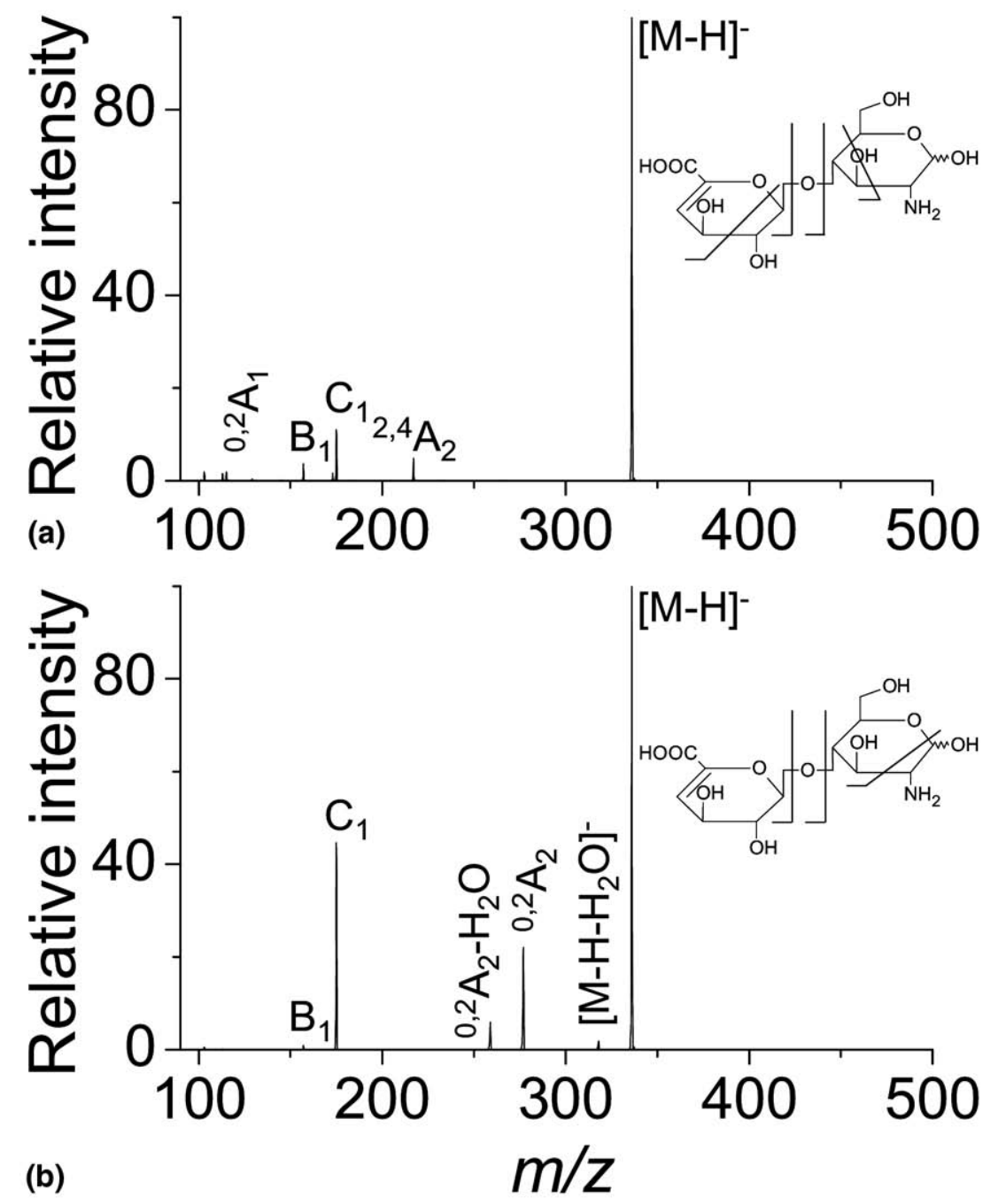

Figure 5. (a) UVPD $(\lambda=240 \mathrm{~nm})$ product ion mass spectrum of $\Delta \mathrm{UA}-\mathrm{GlcN}[\mathrm{M}-\mathrm{H}]^{-}$. Insert, $\Delta$ UA-GlcN structure with major cleavages indicated. (b) CID product ion mass spectrum of $\Delta \mathrm{UA}-\mathrm{GlcN}[\mathrm{M}-\mathrm{H}]^{-}$. Insert, $\Delta \mathrm{UA}-\mathrm{GlcN}$ structure with major cleavages indicated.

excitation of the excess electron localized on the acidic groups that results in partial charge-transfer from the negative site to the bonds in the vicinity of this acidic function. DUA-GlcN6S and $\Delta \mathrm{UA} 2 \mathrm{~S}-\mathrm{Gl} \mathrm{N}$ are expected to be deprotonated on the sulfate group whereas $\Delta \mathrm{UA}$ GlcN is deprotonated on the carboxylate group. So, the transitions leading to the maximum of UV light absorption at $\lambda=240 \mathrm{~nm}$ for the two sulfated disaccharides likely involves electrons localized on the sulfate groups.

Figures $3 a, 4 a$, and $5 a$ show the UVPD spectra at $\lambda=$ $240 \mathrm{~nm}$ recorded after three laser pulses for isolated $[\mathrm{M}-\mathrm{H}]^{-}$ions with respectively $\Delta \mathrm{UA}-\mathrm{GlcN} 6 \mathrm{~S}, \Delta \mathrm{UA2S}-$ GlcN, and $\Delta \mathrm{UA}-\mathrm{GlcN}$ structures. They are similar to those previously reported by Saad and Leary [25]. Figures $3 b, 4 b$, and $5 b$ provide their corresponding CID spectra. In the case of a single shot irradiation (data not shown), identical photofragments with similar relative abundances but with lower signal intensities were observed. Moreover, the total yield of fragmentation increases linearly with laser power, whatever the disac- charide structure, which is in agreement with a parent ion fragmentation driven by a one photon process, as observed in the case of peptides [26]. Most of the fragment ions resulting from CID were also observed in UVPD mode (Table 2). This is an indication that part of the UVPD fragmentation occurs after internal vibrational energy redistribution (IVR) and then global heating of the precursor ions. As expected from our gasphase optical spectroscopic study, the UVPD depletion rate at $240 \mathrm{~nm}$ of $[\mathrm{M}-\mathrm{H}]^{-}$for $\Delta \mathrm{UA}-\mathrm{GlcN}$ heparin derived disaccharide is lower than its two sulfated counterparts.

The pattern of fragment ions stemming from dissociation at the glycosidic bond shows close similarities between UVPD (Figure 3a, 4a, and 5a) and CID (Figure $3 \mathrm{~b}, 4 \mathrm{~b}, 5 \mathrm{~b})$ activation spectra. Thus $\mathrm{Y}_{1}\left(\mathrm{~m} / z\right.$ 258.0) and $\mathrm{Z}_{1}$ $\left(m / z\right.$ 240.0) ions, $\mathbf{B}_{1}-\mathrm{SO}_{3}\left(\mathrm{~m} / z\right.$ 157.0) ion, $\mathrm{C}_{1}(\mathrm{~m} / \mathrm{z}$ 175.0), and $\mathbf{B}_{1}(m / z$ 157.0) ions are observed, respectively, for $\Delta \mathrm{UA}-\mathrm{GlcN6S}, \Delta \mathrm{UA2S}-\mathrm{GlcN}$, and DUA-GlcN disaccharides, whatever the activation method. 
Table 2. List of fragment ions resulting from UVPD at $240 \mathrm{~nm}$ and CID of $[\mathrm{M}-\mathrm{H}]^{-}$ions for DUA GlcN6S, DUA2S-GlcN, and DUA-GlcN disaccharides

\begin{tabular}{|c|c|c|c|}
\hline Ion & Calc. $m / z$ & UVPD Obs. $m / z$ & CID Obs. $\mathrm{m} / \mathrm{z}$ \\
\hline \multicolumn{4}{|l|}{$\Delta$ UA-GIcN6S } \\
\hline$\left[\mathrm{M}-\mathrm{H}-\mathrm{H}_{2} \mathrm{O}\right]^{-}$ & 398.04 & & 398.1 \\
\hline${ }^{0,2} \mathrm{~A}_{2}$ & 357.01 & 357.1 & 357.2 \\
\hline${ }^{0,2} \mathrm{X}_{1}$ & 300.04 & 300.1 & 300.2 \\
\hline$Y_{1}$ & 258.03 & 258.1 & 258.2 \\
\hline${ }^{0,2} \mathrm{X}_{1}{ }^{0,2} \mathrm{~A}_{2}$ & 241.00 & 241.1 & \\
\hline $\mathrm{Z}_{1}$ & 240.02 & 240.1 & 240.1 \\
\hline $\mathrm{Z}_{1}-\mathrm{H}_{2} \mathrm{O}$ & 222.01 & & 222.1 \\
\hline $\mathrm{Y}_{1} /{ }^{0,2} \mathrm{~A}_{2}$ & 199.00 & 199.1 & 199.1 \\
\hline${ }^{0,4} X_{0}$ & 138.97 & 139.1 & \\
\hline $\mathrm{HCO}_{4}^{-}$ & 96.96 & & 97.0 \\
\hline \multicolumn{4}{|l|}{$\Delta$ UA2S-GIcN } \\
\hline$\left[\mathrm{M}-\mathrm{H}-\mathrm{H}_{2} \mathrm{O}\right]^{-}$ & 398.04 & & 398.0 \\
\hline${ }^{0,2} A_{2}$ & 357.01 & 357.1 & 357.2 \\
\hline${ }^{0,2} \mathrm{X}_{1}$ & 300.04 & 300.1 & 300.2 \\
\hline${ }^{0,2} X_{1}{ }^{0,2} A_{2}$ & 241.00 & 241.1 & \\
\hline $\mathrm{B}_{1}$ & 236.97 & 237.0 & 237.1 \\
\hline${ }^{1.5} \mathrm{~A}_{1}$ & 208.98 & 209.0 & \\
\hline $\mathrm{B}_{1}-\mathrm{SO}_{3}$ & 157.01 & 157.1 & 157.1 \\
\hline${ }^{1.3} \mathrm{~A}_{1}$ & 138.97 & 139.0 & \\
\hline $\mathrm{HCO}_{4}^{-}$ & 96.96 & & 97.0 \\
\hline \multicolumn{4}{|l|}{$\Delta U A-G I c N$} \\
\hline$\left[\mathrm{M}-\mathrm{H}-\mathrm{H}_{2} \mathrm{O}\right]^{-}$ & 318.08 & & 318.0 \\
\hline${ }^{0,2} \mathrm{~A}_{2}$ & 277.06 & & 277.0 \\
\hline${ }^{0,2} \mathrm{~A}_{2}-\mathrm{H}_{2} \mathrm{O}$ & 259.05 & & 259.1 \\
\hline${ }^{2,4} \mathrm{~A}_{2}$ & 217.03 & 217.1 & \\
\hline $\mathrm{C}_{1}$ & 175.02 & 175.1 & 175.1 \\
\hline$B_{1}$ & 157.01 & 157.1 & 157.1 \\
\hline${ }^{0,2} A_{1}$ & 115.00 & 115.1 & \\
\hline
\end{tabular}

In contrast, UVPD and CID activation spectra differ markedly in the fragment ion patterns originating from cross-ring cleavage and neutral loss. UVPD spectra are characterized by more intense cross-ring fragmentations of $\mathrm{A}$ and $\mathrm{X}$ series than CID, which in turn favors $\mathrm{H}_{2} \mathrm{O}$ neutral loss. This increase in cross-ring cleavages in UVPD spectra in comparison with CID spectra was also observed with higher photon energy by Reilly and coworkers [27]. In the case of $\triangle \mathrm{UA}-$ GlcN6S disaccharide, UVPD specifically initiates the formation of ${ }^{0,4} X_{0}$ and ${ }^{0,2} X_{1} /{ }^{0,2} A_{2}$ fragment ions next to the ${ }^{0,2} A_{2}$ and ${ }^{0,2} X_{1}$ species common to CID. For the $\triangle \mathrm{UA2S}-\mathrm{GlcN}$ compound the ${ }^{1,3} \mathrm{~A}_{1}$ fragment appears specific to UVPD, whereas for the $\Delta \mathrm{UA}-\mathrm{GlcN}$ structure two cross ring cleavages are restricted to this mode of activation, i.e., ${ }^{2,4} \mathrm{~A}_{2}$ and ${ }^{0,2} \mathrm{~A}_{1}$. In all cases, UVPD leads to more informative cross-ring fragmentations than the CID mode, enabling unambiguous delineation of the sulfate group. All these fragments correspond to cross-ring cleavages that retain the carbon atom to which the sulfate is attached. This specific fragmentation is localized near the initial electronic excitation and may then occur before internal conversion or total IVR. This may be due to the nature of the UV excitation that leads to a partial charge-transfer to and destabilization of the bonds in the vicinity of the sulfate group. Most importantly, sulfate excitation does not result in unspecific $\mathrm{SO}_{3}$ losses.

\section{Conclusion}

The present work reports for the first time on the optical spectra and photodissociation patterns of gas-phase deprotonated anions of three heparin-derived disaccharides. Whereas disaccharide with a carboxylic function displays maximum optical absorption at $\lambda=228 \mathrm{~nm}$, the latter is observed at $240 \mathrm{~nm}$ for sulfated disaccharides. UVPD spectra appear more informative in all cases than CID spectra due to additional cross-ring cleavages that provide key fragment ions informative of the sulfate group location. For sulfated disaccharides, absorption of UV photons at $\lambda=240 \mathrm{~nm}$ mainly leads to the electronic excitation of the sulfate group, which results in specific cross-ring cleavages close to the sulfate group without breaking the $\mathrm{SO}_{3}$ labile bond. This feature is currently being evaluated among larger oligosaccharides derived from acidic proteoglycans. The advantage of combining UVPD or EPD with CID in $\mathrm{MS}^{n}$ experiments for extensive structural analysis of such oligosaccharides, which has already proven to be successful for peptides [12-15], DNA [17, 18], and glycans with higher energy photons[20-22, 27], will also have to be evaluated.

\section{Acknowledgments}

The authors thank Alissa Silva for help during the experimental part of this work.

\section{References}

1. Perrimon, N.; Bernfield, M. Cellular Functions of Proteoglycans-An Overview. Semin. Cell. Dev. Biol. 2001, 12, 65-67.

2. Naggar, E. F.; Costello, C. E.; Zaia, J. Competing Fragmentation Processes in Tandem Mass Spectra of Heparin-Like Glycosaminoglycans. J. Am. Soc. Mass Spectrom. 2004, 15, 1534-1544.

3. Wolff, J. J.; Amster, I. J.; Chi, L. L.; Linhardt, R. J. Electron Detachment Dissociation of Glycosaminoglycan Tetrasaccharides. J. Am. Soc. Mass Spectrom. 2007, 18, 234-244.

4. Wolff, J. J.; Chi, L. L.; Linhardt, R. J.; Amster, I. J. Distinguishing Glucuronic from Iduronic Acid in Glycosaminoglycan Tetrasaccharides by Using Electron Detachment Dissociation. Anal. Chem. 2007, 79, 2015-2022.

5. Wolff, J. J.; Laremore, T. N.; Busch, A. M.; Linhardt, R. J.; Amster, I. J. Influence of Charge State and Sodium Cationization on the Electron Detachment Dissociation and Infrared Multiphoton Dissociation of Glycosaminoglycan Oligosaccharides. J. Am. Soc. Mass Spectrom. 2008, 19, 790-798.

6. Fung, Y. M. E.; Kjeldsen, F.; Silivra, O. A.; Chan, T. W. D.; Zubarev, R. A. Facile Disulfide Bond Cleavage in Gaseous Peptide and Protein Cations by Ultraviolet Photodissociation at $157 \mathrm{~nm}$. Angew. Chem. Int. Ed. 2005, 44,6399 .

7. Gimon-Kinsel, M. E.; Kinsel, G. R.; Edmondson, R. D.; Russel, D. H. Photodissociation of High Molecular Weight Peptides and Proteins in a Two Linear Time of Flight Mass Spectrometer. J. Am. Soc. Mass Spectrom. 1995, 6, 578.

8. Guan, Z.; Kelleher, N. L.; O'Connor, P. B.; Aaserud, D. J.; Little, D. P.; McLafferty, F. W. One Hundred Ninety-Three nm Photodissociation of Larger Multiply-Charged Biomolecules. Int. J. Mass Spectrom. Ion Processes 1996, 157/158, 357.

9. Joly, L.; Antoine, R.; Allouche, A. R.; Broyer, M.; Lemoine, J.; Dugourd, P. Ultraviolet Spectroscopy of Peptide and Protein Polyanions in Vacuo: Signature of the Ionization State of Tyrosine. J. Am. Chem. Soc. 2007, 129, 8428 .

10. Little, D. P.; Speir, J. P.; Senko, M. W.; O'Connor, P. B.; McLafferty, F. W. Infrared Multiphoton Dissociation of Large Multiply Charged Ions for Biomolecule Sequencing. Anal. Chem. 1994, 66, 2809-2815.

11. Ly, T.; Julian, R. R. Residue-Specific Radical-Directed Dissociation of Whole Proteins in the Gas Phase. J. Am. Chem. Soc. 2008, 130, 351-358.

12. Antoine, R.; Joly, L.; Tabarin, T.; Broyer, M.; Dugourd, P.; Lemoine, J. Photo-Induced Formation of Radical Anion Peptides. Electron Photodetachment Dissociation Experiments. Rapid Commun. Mass Spectrom. 2007, 21, 265-268. 
13. Kim, T.-Y.; Thompson, M. S.; Reilly, J. P. Peptide Photodissociation at $157 \mathrm{~nm}$ in a Linear Ion Trap Mass Spectrometer. Rapid Commun. Mass Spectrom. 2005, 19, 1657-1665.

14. Tabarin, T.; Antoine, R.; Broyer, M.; Dugourd, P. Specific Photodissociation of Peptides with Multi-Stage Mass Spectrometry. Rapid Commun. Mass Spectrom. 2005, 19, 2883-2892.

15. Williams, E. R.; Furlong, J. P. P.; McLafferty, F. W. Efficiency of Collisionally-Activated Dissociation and 193-nm Photodissociation of Peptide Ions in Fourier Transform Mass Spectrometry. J. Am. Soc. Mass Spectrom. 1990, 1, 288

16. Diedrich, J. K.; Julian, R. R. Site-Specific Radical Directed Dissociation of Peptides at Phosphorylated Residues. J. Am. Chem. Soc. 2008, 130, 12212-12213.

17. Gabelica, V.; Rosu, F.; Pauw, E. D.; Antoine, R.; Tabarin, T.; Broyer, M.; Dugourd, P. Electron Photodetachment Dissociation of DNA Anions with Covalently or Noncovalently Bound Chromophores. J. Am. Soc. Mass Spectrom. 2007, 18, 1990-2000.

18. Gabelica, V.; Tabarin, T.; Antoine, R.; Rosu, F.; Compagnon, I.; Broyer, M.; De Pauw, E.; Dugourd, P. Electron Photodetachment Dissociation of DNA Polyanions in a Quadrupole Ion Trap Mass Spectrometer. Anal. Chem. 2006, 78, 6564-6572.

19. Wilson, J. J.; Brodbelt, J. S. Infrared Multiphoton Dissociation of Duplex DNA/Drug Complexes in a Quadrupole Ion Trap. Anal. Chem. 2007, 79, 2067-2077.

20. Devakumar, A.; Mechref, Y.; Kang, P.; Novotny, M. V.; Reilly, J. P. Identification of Isomeric N-Glycan Structures by Mass Spectrometry with $157 \mathrm{~nm}$ Laser-Induced Photofragmentation. J. Am. Soc. Mass Spectrom. 2008, 19, 1027-1040.

21. Wilson, J. J.; Brodbelt, J. S. Ultraviolet Photodissociation at $355 \mathrm{~nm}$ of Fluorescently Labeled Oligosaccharides. Anal. Chem. 2008, 80, 51865196.

22. Devakumar, A; Mechref, Y.; Kang, P.; Novotny, M. V.; Reilly, J. P. Laser-Induced Photofragmentation of Neutral and Acidic Glycans Inside an Ion-Trap Mass Spectrometer. Rapid Commun. Mass Spectrom. 2007, 21, 1452-1460.

23. Cocinero, E. J.; Stanca-Kaposta, E. C.; Gamblin, D. P.; Davis, B. G. Simons, J. P. Peptide Secondary Structures in the Gas Phase: Consensus Motif of N-Linked Glycoproteins. J. Am. Chem. Soc. 2009, 131, 1282-1287.

24. Polfer, N. C.; Valle, J. J.; Moore, D. T.; Oomens, J.; Eyler, J. R.; Bendiak, B. Differentiation of Isomers by Wavelength-Tunable Infrared MultiplePhoton Dissociation-Mass Spectrometry: Application to GlucoseContaining Disaccharides. Anal. Chem. 2006, 78, 670-679.

25. Saad, O. M.; Leary, J. A. Delineating Mechanisms of Dissociation for Isomeric Heparin Disaccharides Using Isotope Labeling and Ion Trap Tandem Mass Spectrometry. J. Am. Soc. Mass Spectrom. 2004, 15, $1274-1286$.

26. Antoine, R.; Joly, L.; Allouche, A. R.; Broyer, M.; Lemoine, J.; Dugourd, P. Electron Photodetachment of Trapped Doubly Deprotonated Angiotensin Peptides. UV Spectroscopy and Radical Recombination. Eur. Phys. J. D. 2009, 51, 117-124.

27. Devakumar, A.; Thompson, M. S.; Reilly, J. P. Fragmentation of Oligosaccharide Ions with $157 \mathrm{~nm}$ Vacuum Ultraviolet Light. Rapid Commun Mass Spectrom. 2005, 19, 2313-2320. 